\title{
Diversity of Mycobacterium tuberculosis and drug resistance in different provinces of Papua New Guinea
}

Serej D Ley ${ }^{1,2,3}$, Paul Harino ${ }^{3}$, Kilagi Vanuga ${ }^{4}$, Ruben Kamus ${ }^{5}$, Robyn Carter ${ }^{6}$, Christopher Coulter ${ }^{6}$, Sushil Pandey ${ }^{6}$, Julia Feldmann ${ }^{1,2}$, Marie Ballif ${ }^{1,2}$, Peter M Siba ${ }^{3}$, Suparat Phuanukoonnon ${ }^{3}$, Sebastien Gagneux ${ }^{1,2}$ and Hans-Peter Beck ${ }^{1,2^{*}}$

\begin{abstract}
Background: Papua New Guinea (PNG) is a high tuberculosis (TB) burden country of the WHO Western Pacific Region, but so far research on drug resistance (DR) and genotypes of Mycobacterium tuberculosis (M. tuberculosis) was only conducted in few provinces in the country. The aim of the present study was to obtain baseline data on the level of drug resistance and the genotypic diversity of circulating $M$. tuberculosis in additional provinces and to investigate the differences between three selected sites across PNG.

Results: Genotyping of 147 M. tuberculosis clinical isolates collected in Goroka, Eastern Highlands Province, in Alotau, Milne Bay Province and in Madang, Madang Province revealed three main lineages of M. tuberculosis: Lineage 4 (European-American lineage), Lineage 2 (East-Asian lineage) and Lineage 1 (Indo-Oceanic lineage). All three lineages were detected in all three sites, but the individual lineage compositions varied significantly between sites. In Madang Lineage 4 was the most prevalent lineage (76.6\%), whereas in Goroka and Alotau Lineage 2 was dominating $(60.5 \%$ and $84.4 \%$, respectively) $(p<0.001)$. Overall, phenotypic drug susceptibility testing showed $10.8 \%$ resistance to at least one of the first-line drugs tested. Of all resistant strains (23/212) 30.4\% were Streptomycin mono-resistant, $17.4 \%$ were Isoniazid mono-resistant and $13 \%$ were Rifampicin mono-resistant. Multi-drug resistant (MDR) TB was found in 2.8\% of all tested cases (6/212). The highest amount of MDR TB was found in Alotau in Milne Bay Province (4.6\%).

Conclusion: A large number of drug resistant TB infections are present in the country and MDR TB has already been detected in all three surveyed regions of PNG, highlighting the importance of monitoring drug resistance and making it a high priority for the National Control Program. Due to the high prevalence of Lineage 2 in Milne Bay Province and given the frequent association of this lineage with drug resistance, monitoring of the latter should especially be scaled up in that province.
\end{abstract}

Keywords: Tuberculosis, Papua New Guinea, Genotyping

\footnotetext{
* Correspondence: hans-peter.beck@unibas.ch

${ }^{1}$ Swiss Tropical and Public Health Institute, Basel, Switzerland

University of Basel, Basel, Switzerland

Full list of author information is available at the end of the article
} 


\section{Background}

Over the last decade, evidence for the impact of the bacterial genetic background on TB infection and disease has strongly increased [1]. A phylogeography of $M$. tuberculosis based on large sequence polymorphisms and confirmed by multi-locus sequence analysis could furthermore be established, showing an association between specific M. tuberculosis strains and a particular geographic region $[2,3]$. The different $M$. tuberculosis strains were grouped into 6 main lineages (a 7th was recently added [4]). Various studies investigated the impact of different MTBC lineages on the clinical presentation of the disease. Infection with Lineage 2 has for example been found to be associated with faster progression to disease [5] and drug resistance [6,7]. Lineage 4 on the other hand, has been associated with pulmonary TB rather than extrapulmonary TB [8]. In addition, few studies have analysed the impact of the genetic background of both, humans and bacteria on disease development $[8,9]$ and found correlations between different human genetic polymorphisms with specific $M$. tuberculosis lineages. However, findings from studies investigating lineage specific associations have also reflected within lineage variability $[10,11]$. Therefore, further discriminatory strain differentiation methods should be considered when investigating $M$. tuberculosis genetic diversity. Nevertheless, the various findings support the idea of a longstanding host-pathogen co-evolution and the hypothesis that TB spread together with the human out-of-Africa migration $[2,12,13]$. To investigate the M. tuberculosis genetic diversity within and between different populations could therefore give important insights into the dynamics of $\mathrm{TB}$ disease and might help to inform national TB programs to develop better control strategies.

Papua New Guinea (PNG) is a high TB burden country with an estimated TB incidence rate of 348/100'000 in 2012 and its proportion of multidrug resistance (MDR) estimated at $4.9 \%$ in new cases is higher than the estimated global average of $3.6 \%[14,15]$. Publications on drug resistant TB in PNG are rare, and previous data were mainly derived from patients from Western Province, diagnosed in Australia [16-19]. Gilpin et al. reported 25\% MDR-TB among patients from Western Province diagnosed between 2000 and 2006 [17]. Only two publications on DR data from other provinces exist: Ballif et al. found that $5.2 \%$ of tested isolates of adult patients from Madang were MDR-TB [20], and a recently published study from Kikori in Gulf Province of PNG reported 9\% of suspected MDR-TB (based on Xpert ${ }^{\circ}$ MTB/RIF) in the investigated population [21].

PNG harbours a vast human genetic diversity and has been isolated from the outside world for a long time. PNG was populated through several waves of human migrations and people living in the Highlands represent the oldest population from the first migration wave about 50,000 years ago [22,23]. The highlands region has only been 'discovered' in the 1930s [24] and was sparsely populated at the time. Hence it would be expected that evolutionary 'ancient' lineages of $M$. tuberculosis (e.g. Lineage 1 [25]), proposed to be adapted to low density populations [26], would be found there, whilst the 'modern' lineages such as Lineage 2 and Lineage 4 would be expected at the highly populated coastal regions. However, there is limited information on the TB situation available in PNG. Since various lineages have been found to differ in their prevalence between different regions of the same country (e.g. in Indonesia [27] or Taiwan [28]) it is important to also identify the circulating strains in various communities in PNG. To our knowledge, apart from a previous study conducted in Madang province [29], another study where isolates from patients from Western Province were analysed [17] and a very recent study from Gulf Province [21], no other data on the $M$. tuberculosis population structure from PNG have been published.

The aim of the present study was to obtain baseline data on the level of drug resistance and the genotypic diversity of circulating $M$. tuberculosis in selected sites of three provinces of PNG (Goroka in Eastern Highlands Province, Alotau in Milne Bay Province and Madang in Madang Province) and to investigate the differences between these sites.

\section{Results and discussion}

\section{Study population characteristics}

A total of 449 patients enrolled into our study were diagnosed with TB of any type. From 396 of these patients sputum samples could be collected and of these 335 (74.6\%) samples were available for study purposes (see Figure 1). From 212 (63.3\%) of the available samples $M$. tuberculosis were successfully grown in culture and drug susceptibility testing (DST) was performed. Details of population characteristics per study site are described in Table 1.

TB positivity peaked in the age group of 15 to 34 years, which is consistent with country wide data [30]. And $79.1 \%$ (355/449) of patients clinically diagnosed with TB had no history of the disease indicating ongoing transmission. However, these data cannot be used to extrapolate for the whole country and further investigations are required to analyse the transmission dynamics of the disease in PNG.

Figure 1 depicts the flow of all isolates collected. Of samples sent for culture $67.2 \%$ (225/335) could be recovered showing a positive correlation between initial diagnostic bacterial count and culture success (likelihood ratio $\left.\mathrm{X}^{2}=140.6, \mathrm{df}=4, \mathrm{p}<0.001\right)$. The reduced culture success might be likely due to the long distance transport of samples between laboratories that was experienced with samples from other studies. 


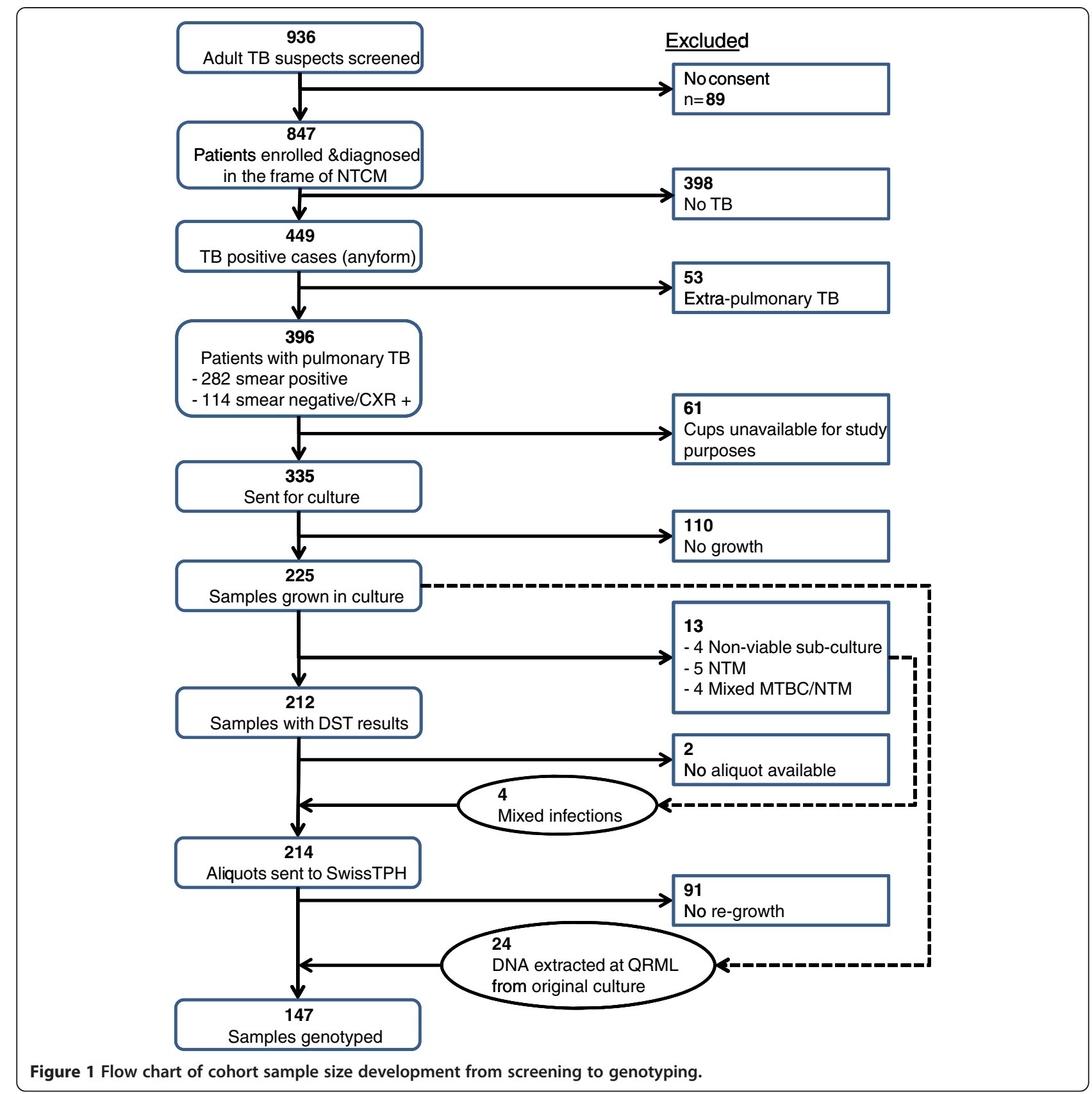

\section{Genotyping}

Genotyping of MTBC could successfully be conducted of 147/212 (69\%) samples. With a TaqMan Real-time PCR assay [31] three of seven worldwide reported MTBC lineages $[3,12]$, were detected in all three study sites. Overall, Lineage 4 was the most prevalent lineage with $75 / 147$ isolates (51.0\%), followed by Lineage 2 with $67 / 147$ isolates (45.6\%), whilst Lineage 1 was rare with $5 / 147$ isolates (3.4\%). This composition of circulating lineages was similar as previously described for Madang [29] and other parts of PNG $[17,21,32]$ and reflects the reduced MTBC diversity within PNG compared to other countries of the region, e.g.
Indonesia [27] or New Zealand [33] where Lineage 3 strains were also found. When lineage compositions (shown in Figure 2) were compared between the study sites, statistically significant differences were observed between all three sites (Fisher's exact test $(\mathrm{p}<0.001)$ ). Lineage 1 was generally rare in all three sites. Lineage 4 was the most abundant lineage in Madang (76.6\%) similar to what has previously been described [29]. In contrast, in Alotau Lineage 2 was the dominant lineage (84.4\%). In Goroka, a trend towards a higher prevalence of Lineage 2 (60.5\%) was found but was not as high as in Alotau. However, it cannot be ruled out that the low proportion of Lineage 1 in our cohort is due to 
Table 1 Characteristics of study population for each study site

\begin{tabular}{|c|c|c|c|c|c|}
\hline \multirow[b]{2}{*}{ Characteristics } & \multicolumn{4}{|c|}{ Drug susceptibility testing result available* } & \multirow{2}{*}{$\begin{array}{l}\text { Total TB positive (any type) } \\
\text { All sites } n=449 n(\%)\end{array}$} \\
\hline & Goroka $n=56 n(\%)$ & Alotau $n=66 n(\%)$ & Madang $n=90 n(\%)$ & Total $n=212 n(\%)$ & \\
\hline \multicolumn{6}{|l|}{ Sex } \\
\hline Male & $32(57.1)$ & $28(42.4)$ & $43(47.8)$ & $103(48.6)$ & $221(49.22)$ \\
\hline Female & $24(42.9)$ & $38(57.6)$ & $47(52.2)$ & $109(51.4)$ & $228(50.78)$ \\
\hline Median age [IQR] & $30[25-40]$ & 29 [24-42] & $30[24-40]$ & $30[24-40]$ & $30[25-42]$ \\
\hline \multicolumn{6}{|l|}{ Age group } \\
\hline 15-24: & $13(23.2)$ & $19(28.8)$ & $27(30.0)$ & $59(27.8)$ & $110(24.5)$ \\
\hline 25-34: & $19(33.9)$ & $23(34.9)$ & $31(34.4)$ & $73(34.4)$ & $157(35.0)$ \\
\hline 35-44: & $12(21.5)$ & $9(13.6)$ & $16(17.8)$ & $37(17.5)$ & $76(16.9)$ \\
\hline 45-54: & $7(12.5)$ & $8(12.1)$ & $9(10.0)$ & $24(11.3)$ & $51(11.4)$ \\
\hline 55-64: & $4(7.1)$ & $4(6.1)$ & $5(5.6)$ & $13(6.1)$ & $40(8.9)$ \\
\hline$>64$ & 0 & $2(3.0)$ & $1(1.1)$ & $3(1.4)$ & $11(2.4)$ \\
\hline missing: & $1(1.8)$ & $1(1.5)$ & $1(1.1)$ & $3(1.4)$ & $4(0.9)$ \\
\hline \multicolumn{6}{|l|}{ Smear result } \\
\hline Smear positive & $55(98.2)$ & $62(93.9)$ & $90(100)$ & 207 (97.6) & $280(62.4)$ \\
\hline Smear negative & $1(1.8)$ & $4(6.1)$ & 0 & $5(2.4)$ & $116(25.8)$ \\
\hline \multicolumn{6}{|l|}{ HIV } \\
\hline $\mathrm{HIV+}$ & $12(21.4)$ & $1(1.5)$ & $3(3.3)$ & $16(7.5)$ & $36(8.0)$ \\
\hline HIV- & $23(41.1)$ & $12(18.2)$ & $43(47.8)$ & $78(36.8)$ & $140(31.2)$ \\
\hline HIV unknown & $21(37.5)$ & $53(80.3)$ & $44(48.9)$ & $118(55.7)$ & $273(60.8)$ \\
\hline \multicolumn{6}{|l|}{ Region of origin } \\
\hline Highlands & $25(44.6)$ & 0 & $3(3.3)$ & $28(13.2)$ & $71(15.8)$ \\
\hline Coast & $4(7.2)$ & $23(34.9)$ & $84(93.3)$ & $111(52.3)$ & $171(38.1)$ \\
\hline Other country & 0 & 0 & $1(1.1)$ & $1(0.5)$ & $1(0.2)$ \\
\hline Unknown & $27(48.2)$ & $43(65.1)$ & $2(2.2)$ & $72(34.0)$ & $206(45.9)$ \\
\hline \multicolumn{6}{|c|}{ History of TB treatment } \\
\hline No & $50(89.3)$ & $42(63.6)$ & 75 (83.3) & 167 (78.8) & 355 (79.1) \\
\hline Yes & $2(3.6)$ & $5(7.6)$ & $11(12.2)$ & $18(8.5)$ & $50(11.4)$ \\
\hline Unknown & $4(7.1)$ & 19 (28.8) & $4(4.5)$ & $27(12.7)$ & $44(9.8)$ \\
\hline
\end{tabular}

*Data of 212 samples for which drug susceptibility was tested compared to 449 enrolled patients diagnosed with any type of TB. IQR = interquartile range.

the strain genetic background itself, e.g. exhibiting reduced transmissibility [34] and a lower growth rate in macrophages compared to Lineage 2 and Lineage 4 [11] potentially leading to a decreased culture recovery of Lineage 1.

We further performed spoligotyping, and the spoligotyping pattern with the corresponding families and frequencies are shown in Figure 3. Thirty different spoligotyping patterns belonged to nine different families, including 14 orphans with 12 different spoligotyping patterns. Orphans were strains with no matching entry in the SITVIT database and are therefore considered as undefined. Whether these strains represent PNG specific $M$. tuberculosis strains remains to be confirmed using other methods.

One of the Lineage 1 strains from Goroka exhibits a special spoligotyping pattern with only spacers $40-43$ being present (sample No. 4 in Figure 3). That spoligotyping pattern has been confirmed with in silico spoligotyping using KvarQ [35]. Per standard definition, this would define that strain as belonging to the Beijing family of Lineage 2 [36,37]. However, SNP-typing assigned this strain to Lineage 1, therefore representing a 'pseudoBeijing' strain with convergent evolution leading to an independent deletion event in the direct repeat locus of MTBC, similar to what has already been described for strains of Lineage 3 [38].

All Lineage 4 samples belonging to the LAM spoligotyping family were exclusively found in Madang, also reflecting the different $M$. tuberculosis lineage composition in the spoligotyping data. All Lineage 2 samples belonged to the Beijing family and were subsequently subtyped into three different monophyletic groups which are sublineages defined by the presence or absence of 


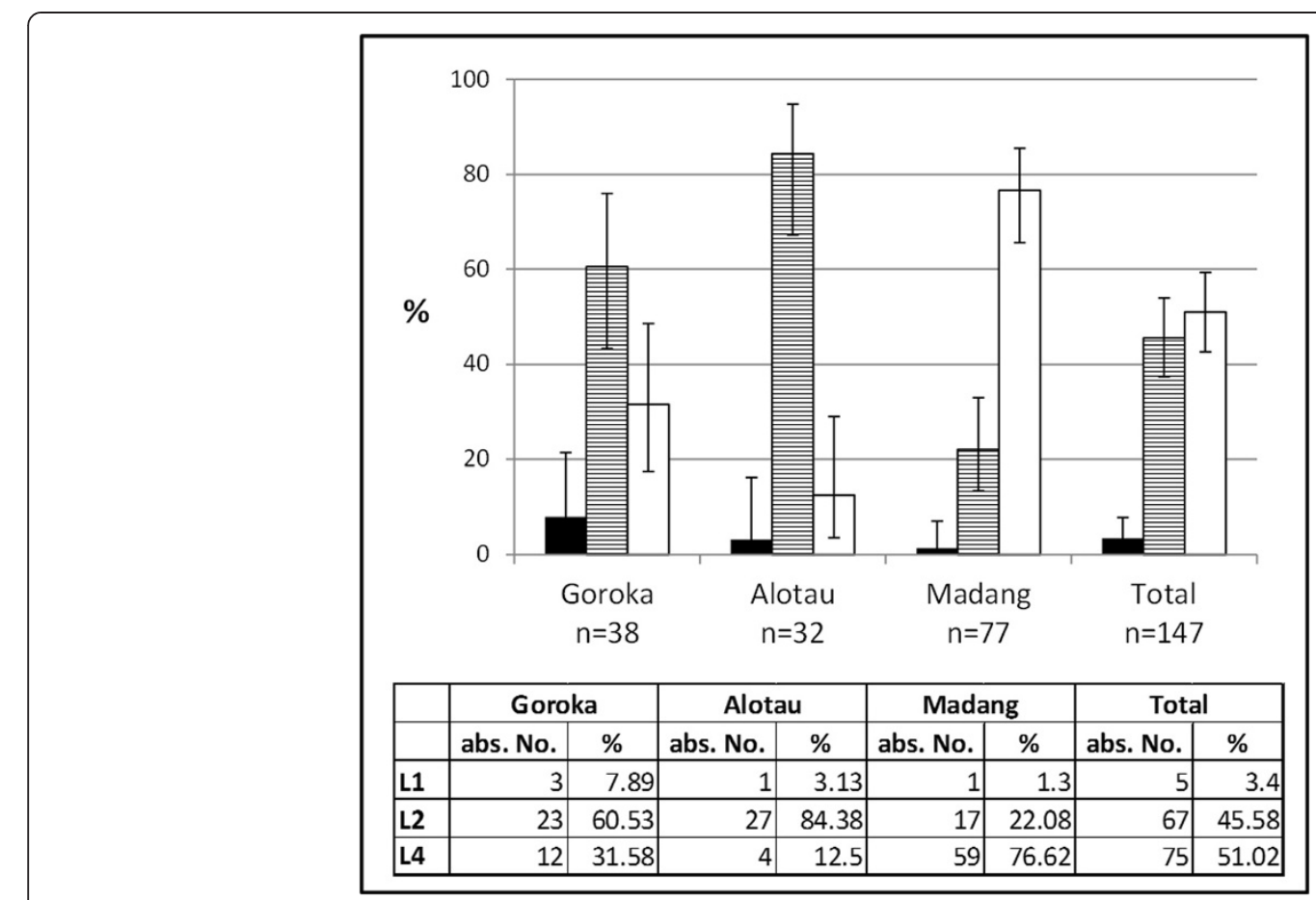

Figure 2 Mycobacterium tuberculosis lineage composition for each study site. Black bars = lineage 1 (Indo-Oceanic); dashed bars = lineage 2 (East-Asian); white bars = lineage 4 (Euro-American).

\begin{tabular}{|c|c|c|c|c|}
\hline Lineage & Spoligotype Pattern & Spoligo Family & SIT & $\mathrm{n}(\%)$ \\
\hline 1 & | & EAI2-MANI & 1501 & $1(0.69)$ \\
\hline 1 & | & EAI5 & 1365 & $2(1.38)$ \\
\hline 1 & | & Orphan & 2590 & $1(0.69)$ \\
\hline 1 & | & Orphan & $\ldots$ & $1(0.69)$ \\
\hline 2 & | & Beijing & 1 & $62(42.76)$ \\
\hline 2 & 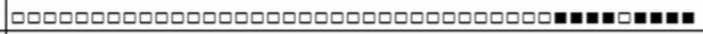 & Beijing & 255 & $2(1.38)$ \\
\hline 2 & | & Beijing & 1651 & $1(0.69)$ \\
\hline 2 & 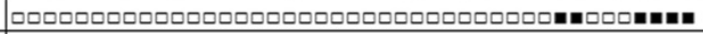 & Beijing & 1941 & $2(1.38)$ \\
\hline 4 & | & H1 & 47 & $2(1.38)$ \\
\hline 4 & 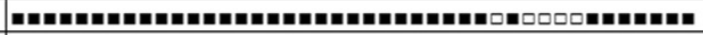 & H3 & 50 & $2(1.38)$ \\
\hline 4 & | & LAM9 & 42 & $4(2.76)$ \\
\hline 4 & | & LAM9 & 1844 & $1(0.69)$ \\
\hline 4 & | & LAM9 & $\ldots$ & $1(0.69)$ \\
\hline 4 & | & T1 & 53 & 25 (19.23) \\
\hline 4 & | & T1 & 102 & $4(3.08)$ \\
\hline 4 & 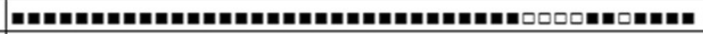 & T1 & 245 & $1(0.77)$ \\
\hline 4 & 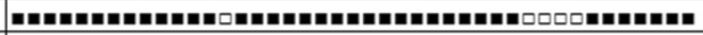 & T1 & 393 & $16(12.31)$ \\
\hline 4 & 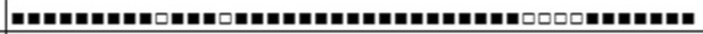 & T1 & 1475 & $1(0.77)$ \\
\hline 4 & | & T2 & 52 & $1(0.77)$ \\
\hline 4 & | & T4-CEU1 & 39 & $2(1.54)$ \\
\hline 4 & 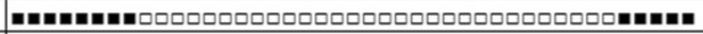 & Orphan & 32 & $1(0.69)$ \\
\hline 4 & | & Orphan & $\ldots$ & $3(2.07)$ \\
\hline 4 & | & Orphan & $\ldots$ & $1(0.69)$ \\
\hline 4 & | & Orphan & $\ldots$ & $1(0.69)$ \\
\hline 4 & | & Orphan & $\ldots$ & $1(0.69)$ \\
\hline 4 & 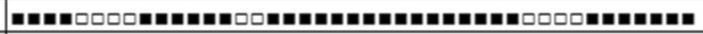 & Orphan & $\ldots$ & $1(0.69)$ \\
\hline 4 & | & Orphan & $\ldots$ & $1(0.69)$ \\
\hline 4 & | & Orphan & $\ldots$ & $1(0.69)$ \\
\hline 4 & | & Orphan & $\ldots$ & $1(0.69)$ \\
\hline 4 & 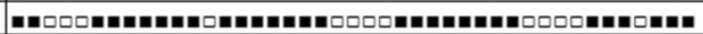 & Orphan & -..- & $1(0.69)$ \\
\hline
\end{tabular}

Figure 3 Spoligotypes for the observed lineages $(n=145)$. SIT = shared international type. 
specific regions of difference (RD) [36]. Over all three sites, one sample of 67 Beijing strains belonged to sublineage 1, here defined as having no deletion of RD181, RD150 or RD142. One sample belonged to sublineage 2 with RD181 deleted but RD150 and RD142 being present, but the majority of Beijing strains (63/65), including all Beijing strains from Alotau, belonged to sublineage 3 with RD180 and RD150 deleted. None of the samples had a deletion for RD142. Sublineage 3 is usually rare, hence the high frequency in our sample is surprising. Several studies have shown that sublineage 3 has rapidly spread in Cape Town, South Africa during the last decade, probably because of a founder effect and/or adaptation to the local host-population [39-41]. Due to the lack of longitudinal data, it is not possible to draw any conclusion about the time of introduction or the duration of spread of this subtype in PNG. However, except for two outliers, our subtyping data based on RDs implies a single introduction of the Beijing strain and a subsequent clonal expansion through PNG. Starting with this observation, it would be important to follow the prevalence of this lineage in Madang and in the country as a whole to monitor a potential increase of Beijing strains in the future.

The reasons for the observed differences in lineage frequencies in the three study sites surveyed remain speculative. These sites differ in several aspects, e.g. Goroka in the Highlands had been much longer isolated from the outside world for much longer than the two coastal sites. The population in the Highlands are believed to be descendants of the oldest human migration wave that populated the country [22], however, no statistically significant difference in the prevalence of Lineage 1 in Goroka could be detected.

Other factors might also influence the lineage distribution. Goroka and Madang are connected to the country through the highlands highway, whilst Madang and Alotau have direct access to the island of PNG and beyond. Similarly, the host genetic background and environmental or circumstantial factors such as co-infections or age could well influence the $M$. tuberculosis lineage distribution. We therefore performed univariate and multivariate logistic regressions to test whether infection with a Lineage 2 strain (equals an infection with Beijing strain) was associated with other factors such as DR, HIV status, age and gender (Table 2). Samples not belonging to Lineage 2 were pooled for the analysis, consisting of five samples of Lineage 1 and 75 samples of Lineage 4. Univariate logistic regression confirmed the differences in lineage distribution between the study sites. These differences remained significant also when correcting for possible confounders in a multivariate regression.

Co-infection with HIV has several times been shown to be associated with infection with strains of the Beijing

Table 2 Univariate and multivariate logistic regressions for the risk of an infection with a Beijing strain of lineage 2

\begin{tabular}{|c|c|c|c|c|c|c|}
\hline \multirow[t]{2}{*}{ Explanatory variable } & \multirow[t]{2}{*}{$\begin{array}{l}\text { Lineage } 2 \\
n=67(45.58 \%)\end{array}$} & \multirow[t]{2}{*}{$\begin{array}{l}\text { Non-lineage } 2 \\
n=80(54.42 \%)\end{array}$} & \multicolumn{2}{|c|}{$\begin{array}{l}\text { Univariate regression: associations } \\
\text { with } M \text {. tuberculosis lineage } 2\end{array}$} & \multicolumn{2}{|c|}{$\begin{array}{l}\text { Multivariate regression: associations } \\
\text { with } M . \text { tuberculosis lineage } 2\end{array}$} \\
\hline & & & $\begin{array}{l}\text { Crude OR } \\
(95 \% \mathrm{Cl})\end{array}$ & p-value & $\begin{array}{l}\text { Adj. OR } \\
(95 \% \mathrm{Cl})\end{array}$ & p-value \\
\hline \multicolumn{7}{|l|}{ Study site $\mathrm{n}(\%)$} \\
\hline Goroka* & $23(34.33)$ & $15(18.75)$ & & & & \\
\hline Alotau & $27(40.30)$ & $5(6.25)$ & $3.5(1.11-11.18)$ & 0.033 & $3.3(1.0-10.8)$ & 0.047 \\
\hline Madang & $17(25.37)$ & $0(75.00)$ & $0.2(0.08-0.43)$ & $<0.001$ & $0.2(0.1-0.4)$ & $<0.001$ \\
\hline Sex, n (\%) & $31(46.27)$ & $37(46.25)$ & $1(0.52-1.91)$ & 0.99 & & \\
\hline Men* & $36(53.73)$ & $43(53.75)$ & & & & \\
\hline \multicolumn{7}{|l|}{ Women } \\
\hline Age - median years [IQR] & $30[25-42]$ & $29[22-40]$ & $1[0.99-1.05]$ & 0.13 & $1.0[0.98-1.1]$ & 0.218 \\
\hline \multicolumn{7}{|l|}{ HIV status } \\
\hline Negative* & $19(63.33)$ & $44(95.65)$ & $12.74(2.57-$ & & & \\
\hline Positive & $11(36.67)$ & $2(4.35)$ & $63.07)$ & 0.002 & & \\
\hline \multicolumn{7}{|l|}{ TB treatment history, $\mathrm{n}(\%)$} \\
\hline $\mathrm{No}^{*}$ & $55(91.67)$ & $66(86.84)$ & & & & \\
\hline Yes & $15(11.03)$ & $10(13.16)$ & $0.60(0.19-1.86)$ & 0.38 & & \\
\hline \multicolumn{7}{|l|}{ Drug resistance (any type) } \\
\hline $\mathrm{No}^{*}$ & $54(83.08)$ & $72(92.31)$ & & & & \\
\hline Yes & $11(16.92)$ & $6(7.69)$ & $2.44(0.85-7.02)$ & 0.097 & $2.5(0.7-8.5)$ & 0.153 \\
\hline
\end{tabular}

*reference category.

$\mathrm{IQR}=$ interquartile range; $\mathrm{OR}=$ odds ratio. $\mathrm{A}$ p-value $<0.05$ was considered statistically significant. 
type $[42,43]$. We also found a significant association between HIV positivity and infection with a Lineage 2 strain $(p=0.002)$, but due to sample size multivariate logistic regression could not be performed. However, HIV prevalence in PNG is still comparably low, in particular in Alotau (2.1\% in Milne Bay Province (Alotau), 5.2\% in Eastern Highlands Province (Goroka) and 2.8\% in Madang Province) [44] and is therefore unlikely to play a major role in the distribution of lineages.

It is important to note that all differences are between the frequencies of Lineage 2 and Lineage 4, whilst Lineage 1 played no major role, although we would have expected more ancient lineages (Lineage 1) in the highlands. Lineage 4 and Lineage 2 are not only the most prevalent M. tuberculosis lineages in PNG, but are also predominating globally [3]. Thus, our findings could support the notion of Hershberg and colleagues [2] that the lineage distribution between and within countries might become homogenized with increasing migration. In other words, more virulent strains such as Lineage 4 and Lineage 2 might slowly replace the ancient lineages as has already been observed in Cameroon [45] and might have started in PNG.

\section{Drug resistance}

In total 23/212 (10.8\%) samples were resistant to at least one of the drugs tested. The details of the DR patterns and their frequency in each study site are shown in Table 3. With $6.6 \%(14 / 212)$ the proportion of isolates resistant (mono-resistant or poly-resistant) to Streptomycin (STR) was the highest in our cohort. High STR resistance in PNG is well known and has been found in previous studies [18-20]. In the past STR has been used frequently as single drug to treat $\mathrm{TB}$ but also urinary tract and Klebsiella infections [46] which might have led to drug resistance. Drug resistance of any type and MDR frequencies were highest in Alotau with $4.6 \%$ of MDR cases, but monoresistance was observed more often in Goroka (8.9\%) and Madang (6.7\%) compared to Alotau (4.6\%). However, none of these differences were statistically significant $(\mathrm{p}=0.960)$.

In order to determine drug resistance mechanisms of 16 phenotypically drug resistant isolates for which DNA could be obtained (16/23), we determined mutations in ten genes known to be associated with resistance. Two pan-susceptible strains of patients with late sputum conversion were also included. Sequence data were analysed and mutations observed are shown in Figure 4.

Streptomycin resistance has been shown to be associated with mutations in the rrs, rpsL or gidB gene [47,48]. For two STR mono-resistant samples only a mutation in gidB was detected (sample 1 in Figure 4) or no mutation was found in any of the analysed genes, respectively (sample 2 in Figure 4). All observed mutations in that gene had also been observed in our previous study in Madang. The sole observation of the synonymous mutation A205G and the non-synonymous mutation A92C in Lineage 2 strains, suggests that these mutations might be lineage specific $[20,49]$ with no mutations occurring in Lineage 4 . In three samples, all belonging to Lineage 4, we found the A10P mutation. In contrast to our previous study where the A10P mutation was absent from 21 pan-susceptible samples, we observed this mutation in one of the pan-susceptible samples (sample 17 in Figure 4), probably suggesting that this

Table 3 Observed phenotypic drug resistance per study site

\begin{tabular}{|c|c|c|c|c|c|}
\hline & & GKA $n=(\%)$ & ALO $n=(\%)$ & MAG $\mathrm{n}=(\%)$ & TOTAL $\mathrm{n}=(\%)$ \\
\hline Pan-susceptible & & $50(89.3)$ & $58(87.8)$ & $81(90.0)$ & 189 (89.2) \\
\hline \multirow[t]{5}{*}{ Monoresistant } & & $5(8.9)$ & $3(4.6)$ & $6(6.7)$ & $14(6.6)$ \\
\hline & STR & 1 & 3 & 3 & 7 \\
\hline & INH (0.1mg/L) & 2 & 0 & 1 & 3 \\
\hline & INH (0.4 mg/L) & 0 & 0 & 1 & 1 \\
\hline & RMP & 2 & 0 & 1 & 3 \\
\hline \multirow[t]{3}{*}{ Polyresistant } & & 0 & $2(3.0)$ & $1(1.1)$ & $3(1.4)$ \\
\hline & $\mathrm{STR}+\mathrm{INH}$ & 0 & 1 & 1 & 2 \\
\hline & $\mathrm{STR}+\mathrm{RMP}$ & 0 & 1 & 0 & 1 \\
\hline \multirow[t]{6}{*}{ MDR } & & $1(1.8)$ & $3(4.6)$ & $2(2.2)$ & $6(2.8)$ \\
\hline & $\mathrm{INH}+\mathrm{RMP}$ & 0 & 0 & 1 & 1 \\
\hline & $\mathrm{STR}+\mathrm{INH}+\mathrm{RMP}+\mathrm{EMB}$ & 1 & 0 & 0 & 1 \\
\hline & $\mathrm{STR}+\mathrm{INH}+\mathrm{RMP}$ & 0 & 2 & 0 & 2 \\
\hline & $\mathrm{STR}+\mathrm{INH}+\mathrm{RMP}+\mathrm{ETH}$ & 0 & 1 & 0 & 1 \\
\hline & $\mathrm{INH}+\mathrm{RMP}+\mathrm{PZA}+\mathrm{ETH}$ & 0 & 0 & 1 & 1 \\
\hline
\end{tabular}




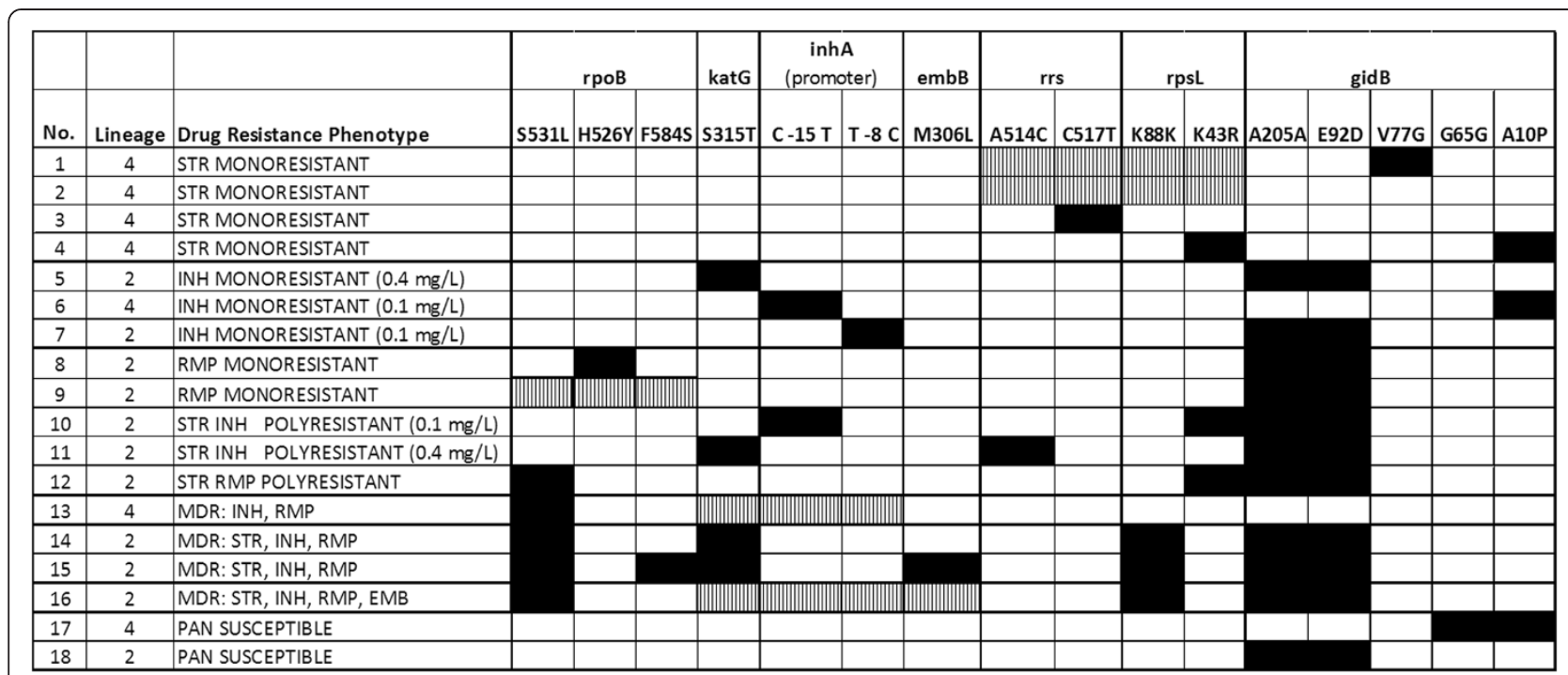

Figure 4 Overview of genes/gene regions sequenced and mutations observed. No mutations were found in ahpC, pncA and gyrA. Black squares: mutation detected at indicated position; white squares: no mutation found at indicated position; dotted squares: no mutation found at any of the indicated positions, which are the most commonly known sites of mutation for the detected phenotypic drug resistance patterns. All positions indicate the amino acid change at the codon position, except for rrs gene where nucleotide position and change is indicated.

mutation plays no role in STR resistance. Whether the mutation V77G found here in one STR resistant strain and yet only described from PNG - is involved in STR resistance [20] remains to be determined.

Ninety-five per cent of the rifampicin (RMP) resistance conferring mutations occur in an $81 \mathrm{bp}$ core region of the so called rifampin resistance determining region (RRDR) [50]. We found only one RMP monoresistant sample (sample 9 in Figure 4) which had no mutation in the 849 bp (including the RRDR) of the $r p o B$ gene we amplified, confirming that RMP resistant strains without a typical mutation in the RRDR are not more common in our sample. This is of crucial importance for the PNG DR surveillance being based on Xpert ${ }^{\circ}$ MTB/RIF (Cepheid) [51] which determines RMP resistance only through detection of mutations in RRDR [52]. However, 26.1\% (6/23) of strains were isoniazid (INH) monoresistant or INH/STR polyresistant. INH resistance is a precursor to MDR-TB and is not detected by the Xpert ${ }^{\circ} \mathrm{MTB} / \mathrm{RIF}$, forming an additional challenge for the control of DR TB that should be addressed by the NTP in the future.

All low level INH resistant samples (resistant to a concentration of $0.1 \mathrm{mg} / \mathrm{L}$ INH) of our study showed a mutation in the inhA promoter region, whereas all high INH resistant samples $(0.4 \mathrm{mg} / \mathrm{L})$ showed a mutation at codon 315 of $k a t G$, including all MDR samples and one of the polyresistant strains with INH and STR resistance (sample 11 in Figure 4). No mutations were detected in the $\operatorname{ahpC}$ promoter region for any of the samples.

Two MDR samples had no mutation in 850 bp of katG sequenced, none in the $a h p C$ promoter or the inh $A$ promoter. One of these samples was also resistant to ethambutol (EMB) (sample 16 in Figure 4) but had no mutation in the $e m b B$ region including codon 306, which is mutated in up to $68 \%$ of clinical EMB resistant strains [48]. For that sample the whole genome sequence was available (data not shown) and was used to screen for mutations outside the amplified regions of katG or embB. Screening revealed a $14 \mathrm{bp}$ deletion at position 2156047 to 2156060 (H37Rv reference, GeneBank AL123456) causing a truncation of katG through a frameshift, explaining the phenotypic high INH resistance of that sample. Outside of the sequenced $e m b B$ region the non-synonymous mutation G406S was found which had already been described in several other studies suggesting its role in EMB resistance $[53,54]$. For the second MDR sample without a $k a t G$ mutation, no sequence data was available and the INH resistance conferring mutation could not be determined. It remains unclear whether a deletion in $k a t G$ or mutations in other genes associated with INH resistance, for example in kasA [50] could be responsible for the INH resistance.

No mutation was found in the amplified regions of $p n c A$ for any of the genotyped isolates. However, since for the only sample with phenotypic pyrazinamide resistance (Table 3) no DNA could be obtained, genotyping of that isolate was not possible.

Possible associations with known risk factors for DR were tested using univariate logistic regressions (Table 4). Risk of being infected with a DR strain was 5.5 times higher for patients with a history of TB treatment and 2.4 times higher for patients infected with an Lineage 2 strain although the latter was not statistically significant $(\mathrm{p}=0.097)$. To correct for possible confounders multivariate logistic regression analysis was conducted and 
Table 4 Univariate and multivariate logistic regressions for the risk of drug resistance

\begin{tabular}{|c|c|c|c|c|c|c|}
\hline \multirow[t]{2}{*}{ Explanatory variable } & \multirow[t]{2}{*}{$\begin{array}{l}\text { Pan-susceptible } \\
n=189(89.15 \%)\end{array}$} & \multirow[t]{2}{*}{$\begin{array}{l}\text { Resistant } \\
n=23(10.85 \%)\end{array}$} & \multicolumn{2}{|c|}{$\begin{array}{l}\text { Univariate regression: } \\
\text { associations with DR }\end{array}$} & \multicolumn{2}{|c|}{$\begin{array}{l}\text { Multivariate regression: } \\
\text { associations with DR }\end{array}$} \\
\hline & & & Crude OR (95\% Cl) & $\overline{p \text {-value }}$ & Adj. OR (95\% Cl) & $\overline{p \text {-value }}$ \\
\hline \multicolumn{7}{|l|}{ Study site $\mathrm{n}(\%)$} \\
\hline Goroka* & $50(26.46)$ & $6(26.09)$ & & & & \\
\hline Alotau & $58(30.69)$ & $8(34.78)$ & $1.1(0.4-3.5)$ & 0.808 & & \\
\hline Madang & $81(42.86)$ & 9 (39.13) & $0.9(0.3-2.8)$ & 0.890 & & \\
\hline \multicolumn{7}{|l|}{ Sex, n (\%) } \\
\hline Men* & $92(48.68)$ & $11(47.83)$ & & & & \\
\hline Women & $97(51.32)$ & $12(52.17)$ & $1.0(0.4-2.5)$ & 0.939 & & \\
\hline Age - median years [IQR] & 29 [24-40] & $31[25-50]$ & $1.0[1.0-1.1]$ & 0.267 & & \\
\hline \multicolumn{7}{|l|}{ HIV status } \\
\hline Negative* & $67(83.75)$ & $11(78.57)$ & & & & \\
\hline Positive & $13(16.25)$ & $3(21.43)$ & $1.4(0.3-5.7)$ & 0.636 & & \\
\hline \multicolumn{7}{|l|}{ TB treatment history, $\mathrm{n}(\%)$} \\
\hline $\mathrm{No}^{*}$ & $155(92.26)$ & $15(71.43)$ & & & & \\
\hline Yes & $13(7.74)$ & $6(28.57)$ & $5.5(1.8-16.8)$ & 0.003 & $4.2(1.1-16.7)$ & 0.040 \\
\hline \multicolumn{7}{|l|}{ Lineage 2} \\
\hline $\mathrm{No}^{*}$ & $72(57.14)$ & $6(35.29)$ & & & & \\
\hline Yes & $54(42.86)$ & $11(64.71)$ & $2.44(0.85-7.02)$ & 0.097 & $3.4(1.0-11.2)$ & 0.041 \\
\hline
\end{tabular}

*reference category.

$\mathrm{IQR}=$ interquartile range; $\mathrm{DR}=$ drug resistance; $\mathrm{OR}=$ odds ratio.

the adjusted odds ratio (OR) for risk of being infected with a DR strain with a history of TB treatment decreased from 5.5 to 4.2 but remained significant ( $\mathrm{p}=$ 0.040). This association highlights the importance of constant access to treatment and compliance for the control of DR TB. Strengthening the DOTS strategy and increasing awareness of TB in the population is crucial also in PNG and needs to be maintained at a high level in order not to delay diagnosis and to prevent the possible spread of TB.

Ballif et al. previously found a significant association between an infection with a Lineage 2 strain and drug resistance in a previous study conducted in Madang $(\mathrm{p}<0.010$, $\mathrm{OR}=5.2$, CI (95\%): 1.8 - 15.1) [29]. Also in our current sample set from Madang a significant association between Lineage 2 strains and drug resistance was found, but only after correction for previous TB treatment $(\mathrm{p}=0.041, \mathrm{OR}=$ 3.4, CI (95\%): 1.0 - 11.2), probably due to the limited sample size (Table 4). To test whether the two sample sets from Madang (Ballif et al. versus Madang samples from current study) differed significantly in the drug resistance data, we compared the results of the drug resistance and Lineage 2 analyses from both sample sets by a $\chi^{2}$ test of ORs, but no significant difference was found $\left(\chi^{2}=0.747\right)$.

Because of the small sample size we also only found a borderline significant association between multiple drug resistance and Lineage 2 infection ( $p=0.058$; CI (95\%)
$0.9-68.4 ; \mathrm{OR}=8$ ): there was an 8 times higher risk of being infected with a polyresistant (resistant to more than one drug but not MDR) or MDR strain when infected with an Lineage 2 strain compared to an infection with a strain of a different lineage (in this case Lineage 4 or Lineage 1).

\section{Conclusions}

The direct comparison of $M$ tuberculosis population structures from distinct sites in PNG demonstrated a statistically significant difference between subpopulations. In Madang Lineage 4 was the dominating lineage, whereas Lineage 2 was more frequently detected in Alotau and Goroka. Although the reasons for the observed significant differences of the circulating $M$. tuberculosis strains between study sites are not yet understood, these differences might have a major impact on disease and transmission dynamics in different populations of PNG. Different control strategies for places with a different $M$. tuberculosis lineage composition are not available yet, i.e. the same control strategies apply for all provinces in PNG, namely to detect cases and treat them accordingly. However, by knowing about the increased prevalence of the Beijing type of $M$. tuberculosis in Milne Bay Province, and with the known association between this lineage and drug resistance, monitoring of the latter should 
especially be scaled up in that province, as it could become a hot spot for drug resistance and MDR TB.

Our data show that a significant number of drug resistant TB infections are present across the country and that MDR TB can already be detected in all three surveyed regions of PNG. Nearly all phenotypical resistances were confirmed by sequence analysis.

No inferences can be made from this study for the whole country because of the small sample size and data being derived from only three major towns. Nevertheless, our findings highlight the importance to monitor drug resistance in PNG, and for making it a high priority for the National TB Control Program.

\section{Methods}

\section{Study sites and patient characteristics}

The study was conducted in three different sites across PNG, one site in each region of PNG: in Madang, Madang Province in the Momase Region; Goroka, Eastern Highlands Province, in the Highlands Region, and in Alotau, Milne Bay Province in the Southern Region of PNG. In Madang, patients were enrolled into the study from November 2010 onwards. In Goroka, patient enrolment started in June 2011 and Alotau was added as a study site in July 2011. In all three study sites enrolment was completed in July 2012. Three consecutive sputum samples were collected from adult TB suspect patients (15 years or older) with chronic productive cough who presented at any department of the provincial hospitals (Modilon Hospital, in Madang; Goroka Provincial Hospital in Goroka; Alotau Provincial Hospital and Gurney Health Centre in Alotau). Questionnaire based interviews were conducted to obtain socio-demographic and behavioural information of each patient. TB was diagnosed by either direct smear light microscopy (Ziehl-Neelson staining), fluorescent microscopy (Morse Stain; TB Fluorescent Stain Kit M, Becton, Dickinson and Company, USA), chest $\mathrm{X}$-ray, clinical examination or a combination of these methods. All TB positive study patients were automatically enrolled into the PNG National TB Program (NTP). Therefore, patient management, i.e. treatment and follow up procedures, was carried out according to the NTP guidelines [51]. For a subset of study patients the HIV status could be obtained from the NTP, which recommends HIV testing of TB positive patients.

\section{Sample processing and drug susceptibility testing}

Sputa were obtained from all tuberculosis patients with pulmonary involvement who were able to produce sputum. Sputum samples were decontaminated according to Petroff's method [55]. Subsequently, these samples were inoculated into Mycobacterial Growth Indicator Tubes (BACTEC $^{\mathrm{Tn}}$ MGIT $^{\mathrm{Tn}} 960$ system; BD, Franklin Lakes, NJ, USA) and sent to the Queensland Mycobacterium
Reference Lab in Brisbane, Australia, for culture and drug susceptibility testing (DST). DST utilising the BACTEC 960 MGIT system was conducted as described previously [29].

\section{Genotyping of Mycobacterium tuberculosis}

DNA was extracted from culture either by InstaGene Matrix (Bio-Rad, Hercules, CA, USA) following the manufacturer's protocol, with one bacterial colony resuspended in $1 \mathrm{ml}$ of $\mathrm{dH}_{2} \mathrm{O}$ as starting material, or by mixing $100 \mu \mathrm{l}$ of $M$. tuberculosis inoculated into Dubos broth (prepared tubed medium for cultivation of mycobacteria; Becton, Dickinson and Company, Maryland, USA) with $100 \mu \mathrm{l}$ distilled water and subsequent heat killing at $90^{\circ} \mathrm{C}$ for 1 hour. The DNA was then used for molecular analyses.

$M$. tuberculosis isolates were classified into the main phylogenetic lineages [12] by a TaqMan real-time PCR assay using single nucleotide polymorphism (SNP) typing [31]. Lineages were further discriminated into families by spoligotyping [56], using a commercial membrane produced by Ocimum Biosolutions Ltd, India (product IM9702). Information on the shared international type (SIT) and the spoligo family were obtained from SITVIT WEB [57]. All Beijing strains were further sub-classified into monophyletic groups based on the presence or absence of the regions of difference (RDs) RD181, RD150 and RD142 as described by Tsolaki et al. [36]. PCR conditions and primers were used as previously described by Gagneux et al. [3].

\section{Drug resistance genotyping}

Of all phenotypically drug resistant strains for which DNA could be obtained, drug resistance associated regions of the following genes were amplified by PCR and sequenced by Macrogen (The Netherlands): $k a t G, r p o B$, ahpC (promoter), inhA (promoter), gidB, pncA, gyrA, rrs, rpsL, embB. Additionally, two fully susceptible isolates of patients for whom smear conversion took longer than the usual 2 months were included. Primers and PCR conditions were used as previously described by Ballif et al. [20] with the following modifications; for $r p o B$ a new set of primers was designed: forward primer 5'AYATCGACCACTTCGGYAACC3', reverse primer 5'TCCTCGATGACGCCGCTTTCT3' $(\mathrm{Y}=$ $\mathrm{C} / \mathrm{T})$. PCR was run with an annealing temperature $\left(\mathrm{T}_{\mathrm{A}}\right)$ of $62^{\circ} \mathrm{C}$, an elongation time $\left(\mathrm{E}_{\mathrm{T}}\right)$ of 60 seconds and 37 cycles, leading to a product length of $849 \mathrm{bp}$. For the inhA promoter and kat $G$ amplification, primers remained the same as published but the $\mathrm{T}_{\mathrm{A}}$ was increased from $60^{\circ} \mathrm{C}$ to $65^{\circ} \mathrm{C}$ and the cycle number from 35 to 39 for inhA, and from $64^{\circ} \mathrm{C}$ to $66^{\circ} \mathrm{C}$ and from 35 to 40 cycles for $k a t G$.

\section{Statistical analysis}

Statistical analysis was carried out with Stata 12.1 (StataCorp, College Station, TX, USA). Differences between study sites were assessed by cross-tabulation and significance 
testing using Fisher's exact and $x^{2}$ testing. P-values $<0.05$ were considered statistically significant. Univariate logistic regressions were performed to assess associations of drug resistance or Lineage 2 infection with known potential predictors or confounders. Independent variables with a significance level of $\mathrm{p}<0.2$ in the univariate analysis and a plausible causal link where further analysed in a multivariate logistic regression. Model selection for multivariate regressions was based on the AIC-criterion. The comparison of two different sample sets from the same study site was done with a $\chi^{2}$ test of odds ratios with $\chi^{2}>3.84$ considered to show a statistically significant difference ( $5 \%$ level).

\section{Ethical approval}

Ethical approval for this study was granted by the PNG IMR Institutional Review Board (IRB No. 0913) and the PNG Medical Research Advisory Council (MRAC No. 10.02). The Ethik-Kommission beider Basel (EKBB) has been informed and had approved the study. Written informed consent was obtained from all study participants.

\section{Competing interests}

The authors declare that they have no competing interests.

\section{Authors' contribution}

SDL: contributed to the study design, implemented and coordinated the study, participated in the sample collection and processing, carried out the molecular analysis, conducted data analysis and drafted the manuscript. PH: contributed to study design and coordinated the study in one of the study sites and was involved in sample collection and responsible for patient management. KV and RK were responsible for patient management. CC, SP and RC supervised culturing and phenotypic DST and helped to draft the paper. JF carried out culturing at Swiss TPH and was involved in the molecular analysis. MB contributed to the study design and was involved in data analysis. SPM: was involved in conceiving the study, contributed to its design and helped to draft the manuscript. PS: contributed to the study design, SG: participated in the design of the study, coordinated the molecular work and helped to draft the paper. HPB: conceived the study and contributed to its design and coordination and acquired the funding for the study and helped to draft the manuscript. All authors read and approved the final manuscript.

\section{Acknowledgements}

We thank all study participants whose samples were collected and analysed as well as the health authorities of Madang Province, Alotau Province and Goroka Province for approving the study and establishing the contact to the hospitals and health centres. We are indebted to the PNG IMR study teams and the hospital staff in all three sites for sample collection, diagnosis, access to infrastructure and general support. The contribution of the staff of the Queensland Mycobacterium Reference Laboratory is gratefully acknowledged. The study was funded by the Stanley Thomas Johnson Foundation and the Medicor Foundation Liechtenstein.

\section{Author details}

${ }^{1}$ Swiss Tropical and Public Health Institute, Basel, Switzerland. ${ }^{2}$ University of Basel, Basel, Switzerland. ${ }^{3}$ Papua New Guinea Institute of Medical Research, Goroka, Papua New Guinea. ${ }^{4}$ Goroka Provincial Hospital, Goroka, Papua New Guinea. ${ }^{5}$ Alotau Provincial Hospital, Alotau, Papua New Guinea. ${ }^{6}$ Queensland Mycobacterium Reference Laboratory, Pathology Queensland, Brisbane, Australia.

Received: 28 July 2014 Accepted: 24 November 2014 Published online: 05 December 2014

\section{References}

1. Coscolla M, Gagneux S: Does M. tuberculosis genomic diversity explain disease diversity? Drug Discov Today Dis Mech 2010, 7:e43-e59.
2. Hershberg R, Lipatov M, Small PM, Sheffer H, Niemann S, Homolka S, Roach JC, Kremer K, Petrov DA, Feldman MW, Gagneux S: High functional diversity in Mycobacterium tuberculosis driven by genetic drift and human demography. PLoS Biol 2008, 6:e311.

3. Gagneux S, Deriemer K, Van T, Kato-Maeda M, de Jong BC, Narayanan S, Nicol M, Niemann S, Kremer K, Gutierrez MC, Hilty M, Hopewell PC, Small PM: Variable host-pathogen compatibility in Mycobacterium tuberculosis. Proc Natl Acad Sci U S A 2006, 103:2869-2873.

4. Firdessa R, Berg S, Hailu E, Schelling E, Gumi B, Erenso G, Gadisa E, Kiros T, Habtamu M, Hussein J, Zinsstag J, Robertson BD, Ameni G, Lohan AJ, Loftus B, Comas I, Gagneux S, Tschopp R, Yamuah L, Hewinson G, Gordon SV, Young DB, Aseffa A: Mycobacterial lineages causing pulmonary and extrapulmonary tuberculosis, Ethiopia. Emerg Infect Dis 2013, 19:460-463.

5. de Jong BC, Hill PC, Aiken A, Awine T, Antonio M, Adetifa IM, Jackson-Sillah DJ, Fox A, Deriemer K, Gagneux S, Borgdorff MW, McAdam KP, Corrah T, Small PM, Adegbola RA: Progression to active tuberculosis, but not transmission, varies by Mycobacterium tuberculosis lineage in The Gambia. J Infect Dis 2008, 198:1037-1043.

6. Bifani PJ, Mathema B, Liu Z, Moghazeh SL, Shopsin B, Tempalski B, Driscol J, Frothingham R, Musser JM, Alcabes P, Kreiswirth BN: Identification of a W variant outbreak of Mycobacterium tuberculosis via population-based molecular epidemiology. JAMA 1999, 282:2321-2327.

7. Van Rie A, Warren RM, Beyers N, Gie RP, Classen CN, Richardson M Sampson SL, Victor TC, van Helden PD: Transmission of a multidrugresistant Mycobacterium tuberculosis strain resembling "strain W" among noninstitutionalized, human immunodeficiency virusseronegative patients. J Infect Dis 1999, 180:1608-1615.

8. Caws M, Thwaites G, Dunstan S, Hawn TR, Lan NT, Thuong NT, Stepniewska K, Huyen MN, Bang ND, Loc TH, Gagneux S, van Soolingen D, Kremer K, van der Sande M, Small P, Anh PT, Chinh NT, Quy HT, Duyen NT, Tho DQ, Hieu NT, Torok E, Hien TT, Dung NH, Nhu NT, Duy PM, van Vinh CN, Farrar J: The influence of host and bacterial genotype on the development of disseminated disease with Mycobacterium tuberculosis. PLoS Pathog 2008, 4:e1000034.

9. van Crevel R, Parwati I, Sahiratmadja E, Marzuki S, Ottenhoff TH, Netea MG, van der Ven A, Nelwan RH, van der Meer JW, Alisjahbana B, van de Vosse E: Infection with Mycobacterium tuberculosis Beijing genotype strains is associated with polymorphisms in SLC11A1/NRAMP1 in Indonesian patients with tuberculosis. J Infect Dis 2009, 200:1671-1674.

10. Kato-Maeda M, Shanley CA, Ackart D, Jarlsberg LG, Shang S, Obregon-Henao A, Harton M, Basaraba RJ, Henao-Tamayo M, Barrozo JC, Rose J, Kawamura LM, Coscolla M, Fofanov VY, Koshinsky H, Gagneux S, Hopewell PC, Ordway DJ, Orme IM: Beijing sublineages of mycobacterium tuberculosis differ in pathogenicity in the guinea Pig. Clin Vaccine Immunol 2012, 19:1227-1237.

11. Reiling N, Homolka S, Walter K, Brandenburg J, Niwinski L, Ernst M, Herzmann C, Lange C, Diel R, Ehlers S, Niemann S: Clade-specific virulence patterns of Mycobacterium tuberculosis complex strains in human primary macrophages and aerogenically infected mice. MBio 2013, 4:e00250-13.

12. Comas I, Coscolla M, Luo T, Borrell S, Holt KE, Kato-Maeda M, Parkhill J, Malla B, Berg S, Thwaites G, Yeboah-Manu D, Bothamley G, Mei J, Wei L, Bentley S, Harris SR, Niemann S, Diel R, Aseffa A, Gao Q, Young D, Gagneux S: Out-ofAfrica migration and Neolithic coexpansion of Mycobacterium tuberculosis with modern humans. Nat Genet 2013, 45:1176-1182.

13. Gagneux S: Host-pathogen coevolution in human tuberculosis. Philos Trans R Soc Lond B Biol Sci 2012, 367:850-859.

14. World Health Organization: Global Tuberculosis Report 2013. 2013. apps.who. int/iris/ bitstream/10665 /91355/1/9789241564656_eng.pdf.

15. WHO: Papua New Guinea Tuberculosis Country Profile. WHO; 2013. http://www.who.int/tb/country/en/.

16. Lumb R, Bastion I, Carter R, Jelfs P, Keehner T, Sievers A: Tuberculosis in Australia: bacteriologically confirmed cases and drug resistance, 2008 and 2009. A report of the Australian Mycobacterium Reference Laboratory Network. Commun Dis Intell 2011, 35:154-161.

17. Gilpin CM, Simpson G, Vincent S, O'Brien TP, Knight TA, Globan M, Coulter C, Konstantinos A: Evidence of primary transmission of multidrug-resistant tuberculosis in the Western Province of Papua New Guinea. Med J Aust 2008, 188:148-152.

18. Simpson G, Coulter C, Weston J, Knight T, Carter R, Vincent S, Robertus L, Konstantinos A: Resistance patterns of multidrug-resistant tuberculosis in Western Province, Papua New Guinea. Int J Tuberc Lung Dis 2011, 15:551-552. 
19. McBryde M: Evalutation of Risks of Tuberculosis in Western Province Papua New Guinea. Australian Aid; 2012. http://aid.dfat.gov.au/countries/pacific/ png/Documents/png-tb-evaluation-of-risk.pdf.

20. Ballif M, Harino P, Ley S, Coscolla M, Niemann S, Carter R, Borrell S, Siba P, Phuanukoonnon S, Gagneux S, Beck HP: Drug resistance-conferring mutations in Mycobacterium tuberculosis from Madang. Papua New Guinea. BMC Microbiol 2012, 12:191

21. Cross GB, Coles K, Nikpour M, Moore OA, Denholm J, McBryde ES, Eisen DP, Warigi B, Carter R, Pandey S, Harino P, Siba P, Coulter C, Mueller I, Phuanukoonnon $S$, Pellegrini M: TB incidence and characteristics in the remote gulf province of Papua New Guinea: a prospective study. BMC Infect Dis 2014, 14:93.

22. Main P, Attenborough R, Chelvanayagam G, Bhatia K, Gao X: The peopling of New Guinea: evidence from class I human leukocyte antigen. Hum Biol 2001, 73:365-383.

23. Yoshida M, Ohtsuka R, Nakazawa M, Juji T, Tokunaga K: HLA-DRB1 frequencies of non-Austronesian-speaking Gidra in south New Guinea and their genetic affinities with Oceanian populations. Am J Phys Anthropol 1995, 96:177-181.

24. Laehy M: The central highlands of New Guinea. Geogr J, 1936, 87.

25. Brosch R, Gordon SV, Marmiesse M, Brodin P, Buchrieser C, Eiglmeier K, Garnier T, Gutierrez C, Hewinson G, Kremer K, Parsons LM, Pym AS, Samper S, van Soolingen D, Cole ST: A new evolutionary scenario for the Mycobacterium tuberculosis complex. Proc Natl Acad Sci U S A 2002, 99:3684-3689.

26. Portevin D, Gagneux S, Comas I, Young D: Human macrophage responses to clinical isolates from the Mycobacterium tuberculosis complex discriminate between ancient and modern lineages. PLoS Pathog 2011, 7:e1001307.

27. Parwati I, Van CR, Sudiro M, Alisjahbana B, Pakasi T, Kremer K, van der Zanden A, van Soolingen D: Mycobacterium tuberculosis population structures differ significantly on two Indonesian Islands. J Clin Microbiol 2008, 46:3639-3645.

28. Chen YY, Chang JR, Huang WF, Kuo SC, Yeh JJ, Lee JJ, Jang CS, Sun JR, Chiveh TS, SU IJ, Dou HY: Molecular epidemiology of Mycobacterium tuberculosis in aboriginal peoples of Taiwan, 2006-2011. J Infect 2014, 68:332-337.

29. Ballif M, Harino P, Ley S, Carter R, Coulter C, Niemann S, Borrell S, Fenner L, Siba P, Phuanukoonnon S, Gagneux S, Beck HP: Genetic diversity of Mycobacterium tuberculosis in Madang, Papua New Guinea. Int J Tuberc Lung Dis 2012, 16:1100-1107.

30. Hiatt T, Nishikiori N: Epidemiology and control of tuberculosis in the Western Pacific Region: analysis of 2012 case notification data. Western Pac Surveill Response J. 2014, 5:25-34.

31. Stucki D, Malla B, Hostettler S, Huna T, Feldmann J, Yeboah-Manu D, Borrell S, Fenner L, Comas I, Coscollà M, Gagneux S: Two new rapid SNP-typing methods for classifying Mycobacterium tuberculosis complex into the main phylogenetic lineages. PLoS One 2012, 7:e41253.

32. Ley SD, Riley I, Beck HP: Tuberculosis in Papua New Guinea: from yesterday until today. Microbes Infect 2014, 16:607-614.

33. Yen S, Bower JE, Freeman JT, Basu I, O'Toole RF: Phylogenetic lineages of tuberculosis isolates in New Zealand and their association with patient demographics. Int J Tuberc Lung Dis 2013, 17:892-897.

34. Albanna AS, Reed MB, Kotar KV, Fallow A, Mclntosh FA, Behr MA, Menzies D: Reduced transmissibility of East African Indian strains of Mycobacterium tuberculosis. PLoS One 2011, 6:e25075.

35. Steiner A, Stucki D, Coscolla M, Borrell S, Gagneux S: KvarQ: targeted and direct variant calling fastq reads of bacterial genomes. BMC Genomics 2014, 15:881.

36. Tsolaki AG, Gagneux S, Pym AS, de la Salmoniere YO G, Kreiswirth BN, Van Soolingen D, Small PM: Genomic deletions classify the Beijing/W strains as a distinct genetic lineage of Mycobacterium tuberculosis. J Clin Microbiol 2005, 43:3185-3191

37. van Soolingen D, Qian L, de Haas PE, Douglas JT, Traore H, Portaels F, Qing HZ, Enkhsaikan D, Nymadawa P, van Embden JD: Predominance of a single genotype of Mycobacterium tuberculosis in countries of east Asia. J Clin Microbiol 1995, 33:3234-3238.

38. Fenner L, Malla B, Ninet B, Dubuis O, Stucki D, Borrell S, Huna T, Bodmer T, Egger M, Gagneux S: "Pseudo-Beijing": evidence for convergent evolution in the direct repeat region of Mycobacterium tuberculosis. PLoS One 2011, 6:e24737.

39. Hanekom M, van der Spuy GD, Streicher E, Ndabambi SL, McEvoy CR, Kidd M, Beyers N, Victor TC, van Helden PD, Warren RM: A recently evolved sublineage of the Mycobacterium tuberculosis Beijing strain family is associated with an increased ability to spread and cause disease. J Clin Microbiol 2007, 45:1483-1490

40. Hanekom M, van der Spuy GD, van Pittius NCG, McEvoy CR, Ndabambi SL, Victor TC, Hoal EG, van Helden PD, Warren RM: Evidence that the spread of Mycobacterium tuberculosis strains with the Beijing genotype is human population dependent. J Clin Microbiol 2007, 45:2263-2266.

41. Cowley D, Govender D, February B, Wolfe M, Steyn L, Evans J, Wilkinson RJ, Nicol MP: Recent and rapid emergence of W-Beijing strains of Mycobacterium tuberculosis in Cape Town, South Africa. Clin Infect Dis 2008, 47:1252-1259.

42. Brites D, Gagneux S: Old and new selective pressures on Mycobacterium tuberculosis. Infect Genet Evol 2012, 12:678-685.

43. Caws M, Thwaites G, Stepniewska K, Nguyen TN, Nguyen TH, Nguyen TP, Mai NT, Phan MD, Tran HL, Tran TH, van Soolingen D, Kremer K, Nguyen W, Nguyen TC, Farrar J: Beijing genotype of Mycobacterium tuberculosis is significantly associated with human immunodeficiency virus infection and multidrug resistance in cases of tuberculous meningitis. J Clin Microbiol 2006, 44:3934-3939.

44. National Department of Health: Papua New Guinea National Health Plan 2011-2020. 2010. http://www.adi.org.au/wp-content/uploads/2013/07/ 2011_AidsCouncilPNG_FACT-SHEET.pdf.

45. Assam JP, Beng VP, Cho-Ngwa F, Toukam M, Ngoh AA, Kitavi M, Nzuki I, Nyonka JN, Tata E, Tedom JC, Skilton RA, Pelle R, Titanji VP: Mycobacterium tuberculosis is the causative agent of tuberculosis in the southern ecological zones of Cameroon, as shown by genetic analysis. BMC Infect Dis 2013, 13:431.

46. Maddocks I, Anders EM, Dennis E: Donovanosis in Papua New Guinea. Br J Vener Dis 1976, 52:190-196

47. Okamoto S, Tamaru A, Nakajima C, Nishimura K, Tanaka Y, Tokuyama S, Suzuki Y, Ochi K: Loss of a conserved 7-methylguanosine modification in $16 \mathrm{~S}$ rRNA confers low-level streptomycin resistance in bacteria. Mol Microbiol 2007, 63:1096-1106.

48. Zhang Y, Yew WW: Mechanisms of drug resistance in Mycobacterium tuberculosis. Int J Tuberc Lung Dis 2009, 13:1320-1330.

49. Spies FS, da Silva PE, Ribeiro MO, Rossetti ML, Zaha A: Identification of mutations related to streptomycin resistance in clinical isolates of Mycobacterium tuberculosis and possible involvement of efflux mechanism. Antimicrob Agents Chemother 2008, 52:2947-2949.

50. Ramaswamy S, Musser JM: Molecular genetic basis of antimicrobial agent resistance in Mycobacterium tuberculosis: 1998 update. Tuber Lung Dis 1998, 79:3-29.

51. National Department of Health, Disease Control Program, National Tuberculosis Program: Papua New Guinea National Tuberculosis Management Protocol. 2011:1-38. http://www.adi.org.au/health-in-png-2/health-reports/\#tb.

52. Hillemann D, Rusch-Gerdes S, Richter E: Evaluation of the GenoType MTBDRplus assay for rifampin and isoniazid susceptibility testing of Mycobacterium tuberculosis strains and clinical specimens. J Clin Microbiol 2007, 45:2635-2640

53. Plinke C, Cox HS, Zarkua N, Karimovich HA, Braker K, Diel R, Rüsch-Gerdes S, Feuerriegel $S$, Niemann S: embCAB sequence variation among ethambutol-resistant Mycobacterium tuberculosis isolates without embB306 mutation. J Antimicrob Chemother 2010, 65:1359-1367.

54. Safi H, Lingaraju S, Amin A, Kim S, Jones M, Holmes M, McNeil M, Peterson SN, Chatterjee D, Fleischmann R, Alland D: Evolution of high-level ethambutol-resistant tuberculosis through interacting mutations in decaprenylphosphoryl-beta-D-arabinose biosynthetic and utilization pathway genes. Nat Genet 2013, 45:1190-1197.

55. Petroff SA: A new and rapid Method for the Isolatin and Cultivation of Tubercle Bacilli directly from the Sputum and Feces. J Exp Med 1915, 21:38-42.

56. Kamerbeek J, Schouls L, Kolk A, van Agterveld M, van Soolingen D, Kuijper S, Bunschoten A, Molhuizen H, Shaw R, Goyal M, van Embden J: Simultaneous detection and strain differentiation of mycobacterium tuberculosis for diagnosis and epidemiology. J Clin Microbiol 1997, 35:907-914.

57. Demay C, Liens B, Burguière T, Hill V, Couvin D, Millet J, Mokrousov I, Sola C, Zozio T, Rastogi N: SITVITWEB - a publicly available international multimarker database for studying Mycobacterium tuberculosis genetic diversity and molecular epidemiology. Infect Genet Evol 2012, 12:755-766.

doi:10.1186/s12866-014-0307-2

Cite this article as: Ley et al:: Diversity of Mycobacterium tuberculosis and drug resistance in different provinces of Papua New Guinea. BMC Microbiology 2014 14:307. 